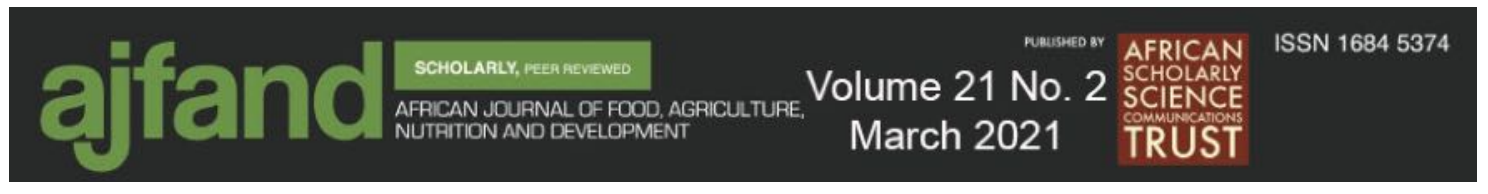

Afr. J. Food Agric. Nutr. Dev. 2021; 21(2): 17464-17476

https://doi.org/10.18697/ajfand.97.19115

\title{
EVALUATION OF IRRIGATION ADEQUACY \\ IN SUGARCANE SYSTEMS IN ESWATINI
}

Shongwe MI $^{1 *}$ and N Tsabedze ${ }^{1}$

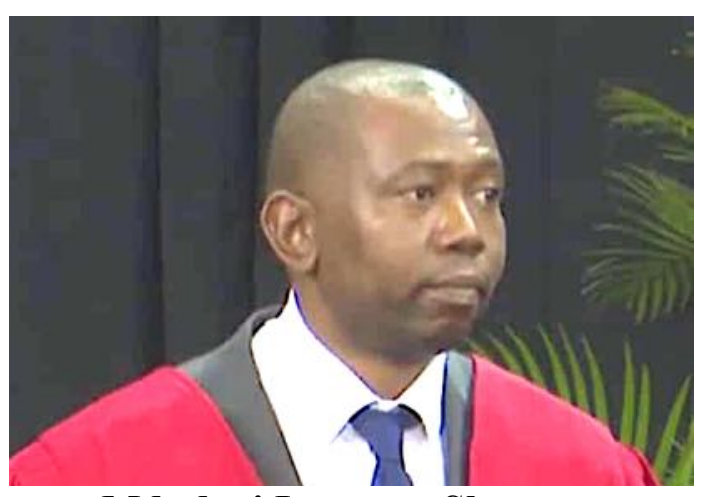

Mduduzi Innocent Shongwe

*Corresponding author email: shongwemi@uniswa.sz

${ }^{1}$ Department of Agricultural and Biosystems Engineering, University of Eswatini,

P. O Luyengo, M205, Eswatini 


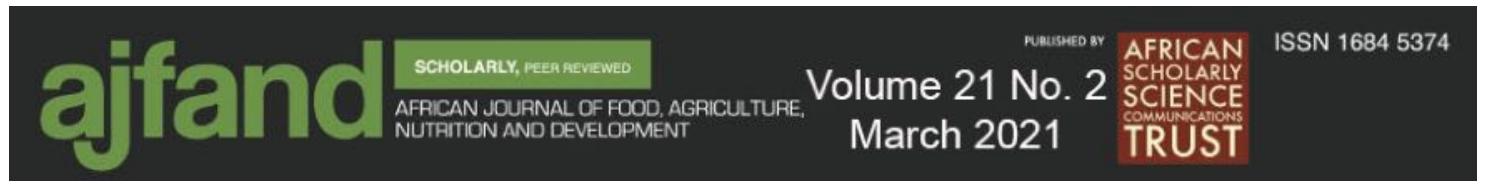

\begin{abstract}
The adoption of objective irrigation scheduling approaches in the sugarcane industry has been very slow leading to over-irrigation, low water use efficiency and consequently, low returns. With the widespread use of subjective scheduling, there is also a perception that there are no significant benefits derived from objective scheduling. A study was, therefore, conducted in Eswatini to determine the performance of irrigation systems that were using subjective irrigation scheduling. More specifically, the objective of the study was to determine the irrigation adequacy for a sugarcane crop that was under two overhead systems viz. centre pivot and sprinkler irrigation. Adequacy was determined in terms of relative irrigation supply (RIS) for the 2015/16 season. The CROPWAT 8.0 model was used to estimate crop demand in terms of net irrigation requirement, whilst the amount of water applied during the period was the supply. Seasonal RIS results indicated that the area under the centre pivot was slightly over-irrigated (RIS $=1.13$ ), whilst irrigation in the area under the sprinkler system was found to be adequate (RIS=0.94). Monthly RIS values, however, revealed that the crop was over-irrigated most of the time. The crop under the centre pivot was over-irrigated for the months of January, June, July, September, November, and December as indicated by the RIS values of 1.17, 1.33, 1.20, 1.77, 3.35, and 15.09, respectively. Over-irrigation under the sprinkler system was observed in June, July, September, October, and November where the RIS was 1.36, 2.19, 2.91, 1.77 , and 1.67, respectively. In both irrigation systems, over-irrigation was experienced at the germination and establishment phases of development. In contrast, all of the months with acceptable RIS values were found to be within the grand growth phase. It was, therefore, concluded that the scheduling approach used in the area was biased towards the grand growth phase. Hence, it was recommended that the irrigation schedule be modified to accommodate each of the different phases of sugarcane development.
\end{abstract}

Key words: irrigation scheduling, adequacy, sugarcane, centre pivot, sprinkler, crop water requirement, CROPWAT 


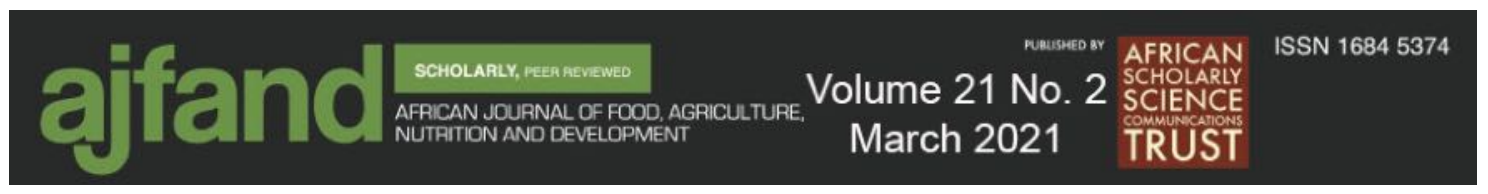

\section{INTRODUCTION}

Agriculture is by far the largest consumer of the freshwater. An estimated $70 \%$ of all freshwater withdrawals from watercourses and groundwater are used for agricultural purposes. By the year 2050, it is estimated that the global water demand for agriculture would have increased by a further $19 \%$ mainly due to irrigation needs [1]. Globally, however, water is being reduced into a scarce resource as competition for water and climate change becomes a reality. Research shows that climate change will continue to impact water resources in the foreseeable future especially in sub-Saharan Region $[2,3]$. The anticipated impact includes, amongst others, severe droughts and an increase in temperatures. Climate change and the increased competition for water as a consequence gradually forces agriculture to account for all water use. Improved irrigation water management as such is becoming more essential for efficient irrigated agriculture.

Improved irrigation water management is realised through proper systems designs and management that ensure that crop water requirement (CWR) is met whilst also controlling deep percolation, runoff, evaporation and operational losses. Since irrigation systems deliver water to the crop root zone, it is important, therefore, that their performance is quantified and evaluated periodically. An important performance parameter that is widely used other than efficiency and uniformity is irrigation adequacy. Irrigation adequacy is a measure of the amount of water supplied to the crop relative to CWR. Any management approach that improves irrigation adequacy and uniformity consequently advances efficiency. Also, without good uniformity, it is impossible to irrigate adequately and efficiently [4]. Irrigation scheduling as such, should be prioritised on any intervention towards improved irrigation management.

Irrigation scheduling defines the day-to-day management of irrigation to maintain optimum CWR. The main purpose of scheduling is to determine the quantity of water required by any crop during peak demand periods and how often that water is to be applied, taking practical operating practices into consideration. The scheduling of irrigation is critical as excessive irrigation raises water tables, and this leads to salinization, reduction in crop yield and unexpected high drainage costs [5]. Underirrigation conversely, causes crop stress and ultimately, reduced yield. Irrigation scheduling can be subjective and/or objective. Objective scheduling conventionally is based on soil-water measurement, plant-based monitoring and/or integrated soil water balance methods [6]. Subjective or intuitive scheduling on the other hand, is based on perceived crop water requirements built upon the farmer's instinct, knowledge and experience gained over time [7]. According to Stevens et al. [8], most farmers in South Africa prefer to use subjective scheduling over objective. An earlier study by Montagu and Stirzaker [9] found that $67 \%$ of farmers in Australia preferred subjective scheduling approaches. Similar work in South Africa found that $80 \%$ of farmers use intuitive scheduling [8]. Even though this may be the case, without support, inexperienced farmers are bound to lack the necessary skill and knowledge to make proper scheduling decisions.

The sugar industry is the cornerstone of the economy of Eswatini (formerly Swaziland). On its own, the sugar industry represents an annual revenue in excess of US\$ 400 


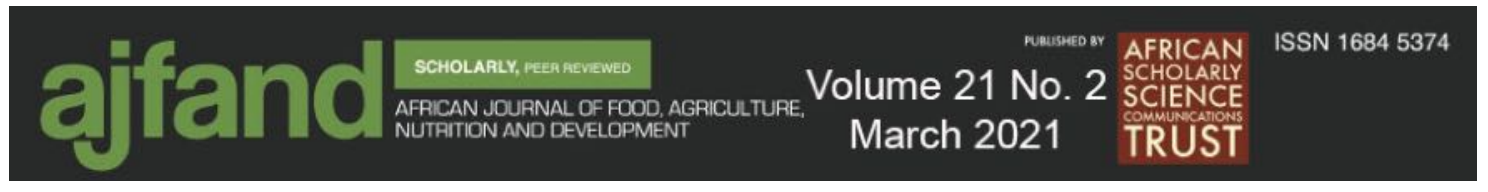

million [10]. The sustainability of this industry is, however, heavily dependent on irrigation management since all the sugarcane grown in Eswatini is irrigated. Complicating matters is the fact that most of the sugarcane in Eswatini is grown in the Lowveld region of the country, where annual rainfall is predominantly low and sporadic especially when compared to the other agro-ecological zones (Highveld, Middleveld and Lubombo). This, coupled with the recent droughts and increased competition for water, is pushing the sugarcane industry towards water conserving practices such as the adoption of drip irrigation systems.

Even though there are strong strides to water conservation in the sugarcane industry, there is still widespread use of subjective irrigation scheduling approaches. According to Singels and Smith [11], the adoption of objective scheduling approaches especially in the South African sugarcane industry, has been very slow leading to over-irrigation, low water use efficiency and consequently, low profits. The slow adoption is often attributed to the complexity of the technology and the difficulty of applying it in practice [11,12]. With the widespread use of subjective scheduling, there is also a perception that there are no significant benefits derived from the use of objective scheduling $[8,11]$. This study was, therefore, conducted in Eswatini to determine the performance of irrigation systems that were under a subjective irrigation scheduling approach. More specifically, the objective was to determine irrigation adequacy for a sugarcane crop under two overhead systems viz. centre pivot and sprinkler irrigation. Irrigation system performance assessments are essential as these are used to detect systemic water losses hence, allow decision-makers to modify and/or improve current practices. Such assessments are important especially for sugarcane where irrigation scheduling approaches are largely influenced by the type of irrigation system in use [12]. Although uniformity is an important aspect in irrigation systems performance, adequacy explains performance better as it indicates the ability to deliver the amount of water required at the effective root zone, hence is an effective measure of irrigation scheduling [13]. The study was also important, considering that the area under investigation had not yet initiated such periodic evaluations of performance to guide continuous improvement.

\section{METHODS}

The study was carried out at a farm located in south-eastern Eswatini. The area is semiarid and its average annual rainfall ranges between 600 and $700 \mathrm{~mm}$ [14]. The soils are yellowish brown loamy sand to sandy loam with a weak to moderate structure and are classified as chromic luvisols in the FAO Soil Classification System [15]. The farm occupied an area of approximately 2000 ha of irrigated sugarcane. Two fields within the farm were selected for this research viz. one irrigated by a centre pivot and the other, a semi-solid sprinkler system.

Irrigation adequacy of both irrigation systems was computed from water supply and CWR data. Crop water requirement was estimated through the CROPWAT 8.0 model [16]. The CROPWAT model is a decision support tool that calculates reference evapotranspiration $\left(E T_{o}\right)$ and crop irrigation requirements. More specifically, the CROPWAT model is used in the design and management of irrigation. Calculation of $E T_{o}$ in the 


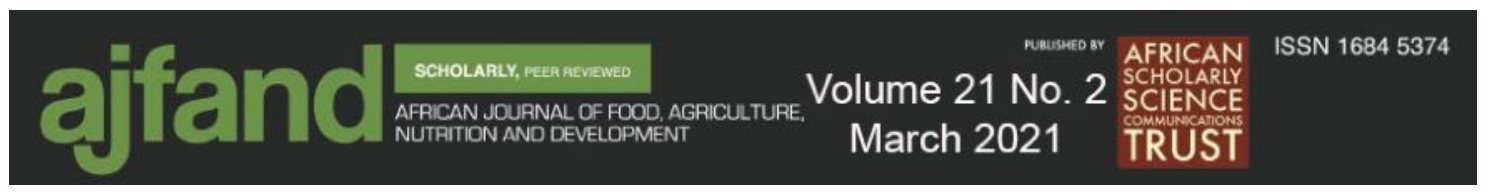

CROPWAT is based on the Penman-Monteith model (equation 1). The PenmanMonteith model is a function of radiation, temperature, vapour pressure, and wind speed. According to Zotarelli et al. [17], the Penman-Monteith model offers the best results with minimum possible error.

$E T_{o}=\frac{0.408 \Delta\left(R_{a}-G\right)+\gamma \frac{900}{T+273} u_{2}\left(e_{s}-e_{a}\right)}{\Delta+\gamma\left(1+0.34 u_{2}\right)}$

where:

$$
\begin{aligned}
& R_{a}=\text { net radiation at the crop surface }\left(\frac{M J}{m^{2}} / \text { day }\right) \\
& G=\text { soil heat flux density }\left(\frac{M J}{m^{2}} / \text { day }\right) \\
& T=\text { mean daily air temperature at } 2 \mathrm{~m} \text { height }\left({ }^{\circ} \mathrm{C}\right) \\
& u_{2}=\text { wind speed at } 2 \mathrm{~m} \text { height }(\mathrm{m} / \mathrm{s}) \\
& e_{s}=\text { saturation vapour pressure }(\mathrm{kPa}) \\
& e_{a}=\text { actual vapour pressure }(\mathrm{kPa}) \\
& \Delta=\text { slope of saturation vapour pressure curve at temperature } T\left(\mathrm{kPa} /{ }^{\circ} \mathrm{C}\right) \\
& \gamma=\text { psychrometric constant }\left(\mathrm{kPa} /{ }^{\circ} \mathrm{C}\right)
\end{aligned}
$$

The study was conducted during the 2015/16 cropping season. The 2015/16 season was selected for this research because it was a drought season and the researchers were of the view that irrigation scheduling and water management, in general, are often high priority with management during such periods [18]. The input into the CROPWAT model in the study included data on climate, crop, and soil. Data on irrigation scheduling including irrigation date and amount applied were obtained from farm records. Also, the dates for planting and drying-off date were collected from records. Monthly rainfall data were collected from the local meteorological station. Data on the soil's characteristics viz. field capacity, permanent wilting point and infiltration rate were sourced from literature specific to the study area. Climatic data which included humidity, temperature, sunshine duration, and wind speed were auto-generated from the CROPWAT model by inserting the name of the local meteorological station.

Water requirement as calculated in this research was in terms of net irrigation $\left(I_{n e t}\right)$. Net irrigation is the quantity of water applied by irrigation to supplement stored soil water, precipitation and groundwater contributions. Net irrigation also considers leaching requirements. In this research, however, $I_{\text {net }}$ was computed as shown in equation 2 .

$I_{n e t}=\left(K_{c} \times E T_{o}\right)-R_{e}$

where:

$$
\begin{aligned}
& R_{e}=\text { effective rainfall }(\mathrm{mm}) \\
& K_{c}=\text { crop coefficient }
\end{aligned}
$$

Effective rainfall, which is the portion of rainfall that is directly useful to the crop, was calculated using the USDA soil conservation method [19].

$R_{e}=S F\left(0.70917 P^{0.82416}-0.11556\right) 10^{0.2426 E T_{c}}$

where:

$$
R_{e}=\text { average monthly effective rainfall (mm) }
$$




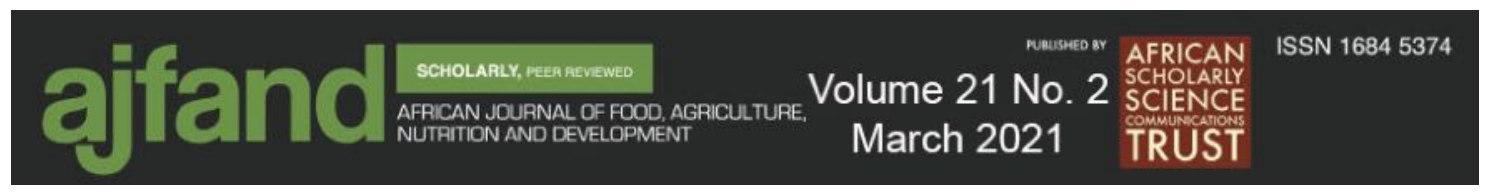

$$
\begin{aligned}
& P=\text { monthly mean rainfall }(\mathrm{mm}) \\
& E T_{c}=\text { average monthly crop evapotranspiration }(\mathrm{mm})\left[E T_{c}=K_{c} E T_{o}\right] \\
& S F=\text { soil water storage factor }
\end{aligned}
$$

The amount of water applied per month $\left(I_{S}\right)$ throughout the $2015 / 16$ season was calculated from the irrigation data sourced from the farm. The data included information on dates of irrigation, gross irrigation per event and irrigation cycle. Based on crop evapo-transpiration output from the CROPWAT model and the irrigation applied to the crop, relative irrigation supply (RIS) was computed for each month. Relative irrigation supply is the most comprehensive measure of adequacy as it relates total irrigation supply to the net irrigation requirement [20]. The RIS gives some indication on the condition of water abundance or scarcity and how tightly supply and demand are matched. The RIS was calculated as indicated in equation 4. An adequacy of less than 1(one) indicates under-irrigation whilst that of a value greater than 1(one) indicates over-irrigation. The recommended acceptable range as such is 0.9-1 [21]. Dinka [22], however, proposes that a deviation of $-20 \%$ and $+10 \%$ from $100 \%$ should be acceptable;

$R I S=\frac{I_{S}}{I_{\text {net }}}$

\section{RESULTS AND DISCUSSION}

Brown soils were selected from the CROPWAT model based on the fact that the local soils were yellowish brown loamy sand to sandy loam [15]. According to the Remmelzwaal and Masuku [23], the effective depth of the soil in the area was more than $150 \mathrm{~cm}$. The average rooting depth of sugarcane is $150-200 \mathrm{~cm}$ hence, a depth of $150 \mathrm{~cm}$ was used in the study since the sugarcane was a plant crop (not a ratoon) [24]. The crop coefficient for the initial stage of growth was 0.4 whilst that for the development and late stage was 1.25 and 0.75 [25]. The soil's infiltration rate, field capacity and permanent wilting point were $30 \mathrm{~mm} / \mathrm{hr}, 140 \mathrm{~mm} / \mathrm{m}$ and $20 \mathrm{~mm} / \mathrm{m}$, respectively. The planting and drying-off date for the field under the centre pivot was $2^{\text {nd }}$ November 2015 and $24^{\text {th }}$ September 2016, respectively. The area under sprinkler irrigation was planted on $5^{\text {th }}$ September 2015 and drying-off commenced on $12^{\text {th }}$ July 2016. The scheduling strategy was to apply $20 \mathrm{~mm}$ of water every 3-4 days, adjusted only in cases of rainfall.

Figure 1 shows the monthly $I_{\text {net }}$ (net irrigation requirement) plotted against the $I_{s}$ (water supplied) and monthly rainfall (2015/2016 season) for the centre pivot system. Also indicated in Figure 1 are the four phases of sugarcane growth viz. germination and establishment, tillering, grand growth or yield formation, and the ripening phase or drying-off [26]. As shown, only the RIS for the month of May (1.0) and August (0.91) were within the acceptable range of 0.9-1.0 as recommended by Ascough and Kiker [21]. In most of the months, the crop was either under- or over-irrigated. In the months of November, December, January, June, July, and September the crop was overirrigated as indicated by RIS values of $3.35,15.09,1.17,1.33,1.20$, and 1.77, respectively. The RIS for the month of December was extremely high (15.09) and this 


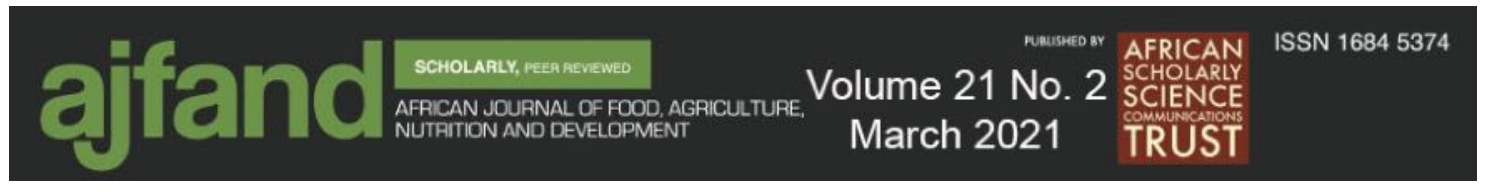

may be attributed to the fact that rainfall was the highest $(83 \mathrm{~mm})$ for the season during this month and coincidentally, December also had the third lowest monthly $E T_{c}$ (72.4 $\mathrm{mm}$ ) in the season. Despite these conditions, however, an additional $80 \mathrm{~mm}$ of water was applied hence, the high RIS.

The months of November, December and January were within the germination and establishment phases of crop development whilst June, July and August formed the grand growth phase. Over-irrigation at the germination and the establishment phases, which in the tropics lasts about 60 days from the date of planting (DAP), reduces soil aeration and this could lead to bud rotting and fungal attacks as activation and sprouting occurs during this phase [27]. According to Wang and Xing [28], overirrigation also reduces nitrogen levels within the root zone. The overall seasonal RIS for the area under the centre pivot system was 1.13, indicating an annual irrigation surplus of $118.1 \mathrm{~mm}(937.9-1056 \mathrm{~mm})$.

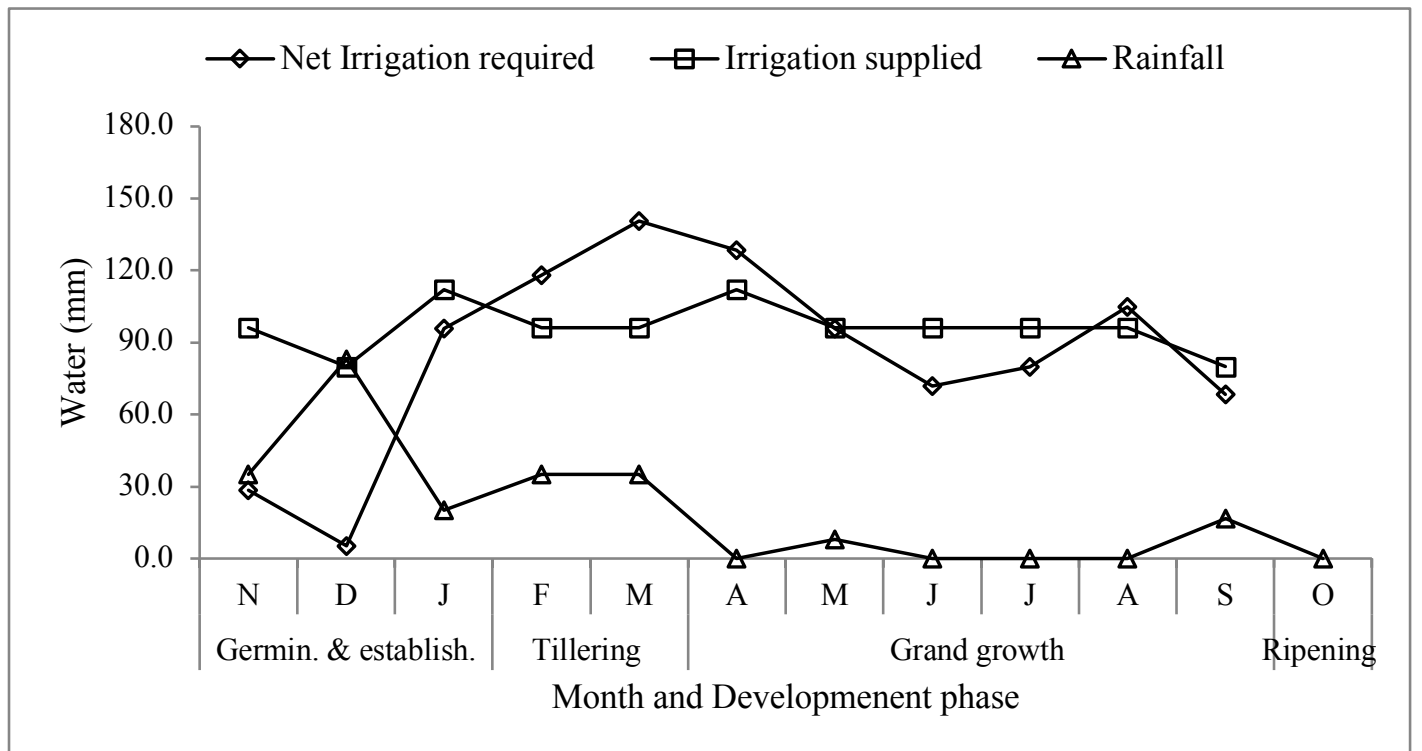

Figure 1: Irrigation required and supplied for the centre pivot portion $(2015 / 16)$

The months of April, May, June, July, and August were within the grand growth phase (120-270 DAP), which is the most critical, wherein actual sugarcane formation and elongation takes place. Over-irrigation of the crop at this phase is somehow preferred over under-irrigation as the latter reduces stalk elongation and could consequently cause low crop weight at harvesting. However, in an experiment that partitioned the grand growth phase into four six-week periods, Wiedenfeld [29] concluded that withholding irrigation in only one of these periods resulted in relatively small yield and sucrose reductions. The ripening phase in the area under the centre pivot began in September and as it is shown in Figure 1, the amount of water applied during this month exceeded the $I_{n e t}$. Drying-off is meant to reduce the rate of vegetative growth and to convert total sugars to recoverable sucrose. Over-irrigation at this stage, conversely, promotes vegetative growth and reduces sucrose content. 


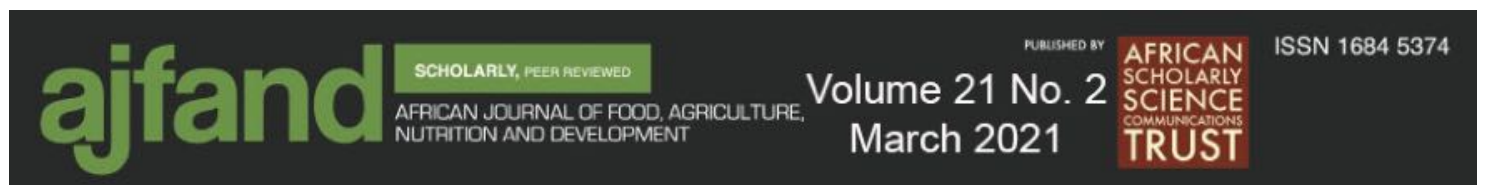

The RIS for the months of February, March and April were 0.84, 0.68 and 0.87, respectively. These values are below the Ascough and Kiker [21] adequacy threshold, which means that the crop was under-irrigated in these months. The RIS values for February (0.84) and April (0.87) were, however, within the acceptable range of -20\% as recommended by Dinka [22]. Under-irrigation in this case was, therefore, assumed to have only occurred in the month of March. The month of March was between tillering (60-120 DAP) and the grand growth phase. Tillering describes the physiological process of continuous underground branching of node joints to provide the crop with the necessary number of stalks. Water shortage at this phase increases tiller mortality, which ultimately decreases stalk population [30]. Research by Robertson et al. [31], however, found that water deficit at tillering has no significant effect on yield, partly due to compensatory growth that takes place once irrigation resumes again.

The annual net irrigation requirement for the area under the sprinkler system was 1046 $\mathrm{mm}$, whilst the net water applied was $980 \mathrm{~mm}$. This shows an annual deficit of $66 \mathrm{~mm}$. Figure 2 shows the monthly trend of $I_{s}$ and $I_{n e t}$. The graph shows that the field was under-irrigated for four months. These were the months of December, January, February, and March with RIS values of $0.72,0.52,0.73$, and 0.61 , respectively. The month of December was within the germination phase whilst January, February and March were within the grand growth phase. Irrigation was considered adequate for the month of April and May where the RIS was 0.83 and 0.89 , respectively. Over-irrigation was observed on five of the season's month's viz. June, July, September, October, and November where the RIS was 1.36, 2.19, 2.91, 1.77, and 1.67, respectively. Overall, the seasonal RIS for the field under the sprinkler system was 0.94 , which indicates an acceptable adequacy level.

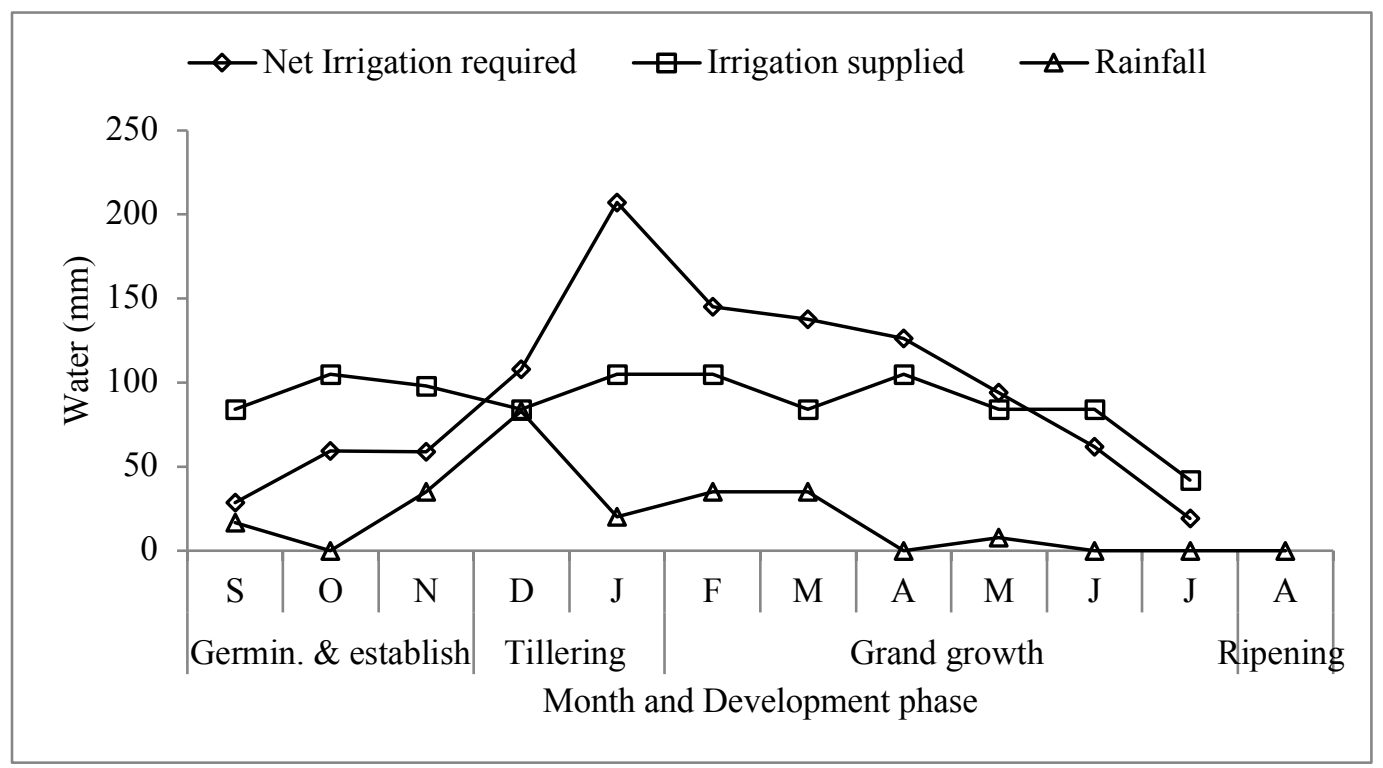

Figure 2: Irrigation required and supplied for sprinkler irrigation (2015/16)

The annual RIS of 1.13 and 0.94 for the area under centre pivot and sprinklers, respectively, indicates that the irrigation scheduling strategy used in the area was 


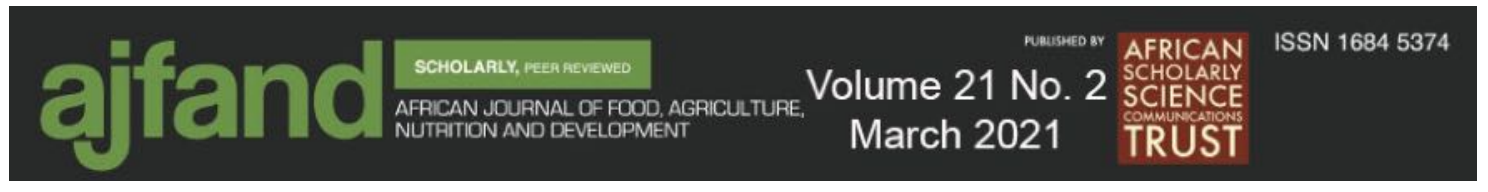

almost successful in achieving the expected RIS. This shows that the farmer may have a better understanding of the irrigation requirements of the crop. Similar research has found the seasonal RIS in Burkina Faso, Egypt, Morocco and Niger to range between 1.1 and 3.5 [32]. Compared to the regional RIS values, the values from the study area were on the lower end, which was rather desirable [32].

There was, however, a wide variation in terms of the monthly RIS values. According to Verma et al. [33], large variations in water demand and supply during the different phases of sugarcane growth may cause wide fluctuations in yield. The monthly RIS values show that in $50 \%$ of the months (11 out of 22 ) the crop was over-irrigated. In both areas, over-irrigation was practiced at the germination and establishment phases (September, October and November for sprinkler and November, December and January for the area under centre pivot). Crop evapo-transpiration is, however, lowest at the germination and establishment phase since evaporation is more important than transpiration [25]. Also the crop coefficient (equation 2) at this phase is lowest [33]. Complicating matters in the study area was that the low $E T_{c}$ (during the germination and establishment phase) coincided with months that experienced the highest precipitation in the season (November and December). The over-irrigation during this phase and time of the year, therefore, may indicate a struggle in determining the correct irrigation cycle especially after rainfall events.

All of the months with acceptable RIS values were within the grand growth phase (with the exception of August in the area under the centre pivot system). This could mean that the scheduling approach in use may have been designed largely based on the grand growth phase of development. This is understandable considering that water demand is highest during the grand growth phase taking into account its duration (up to 21 weeks), and given that there is an increase in crop canopy during this phase. A study by Verma et al. [33] found sugarcane to consume about $6.4 \%, 26.8 \%, 53.6 \%$, and 13.2 $\%$ of water during the germination and establishment phase, tillering, grand growth, and the ripening phase, respectively.

The over-irrigation experienced in the month of June and July (in both irrigation systems) could also indicate bias on the schedule towards the grand growth phase. In both months (June and July), the rainfall received was zero, hence, over-irrigation in this case may show that the depth of water supplied and/or the irrigation cycle was unsuitable more especially because these months were found on two different growth phases viz. grand growth for centre pivot and the ripening phase in the area under sprinklers.

Assuming that the irrigation cycle of 3-4 days remains the same, under-irrigation in the area especially at the critical phases of tillering and grand growth phase could be mitigated by adjusting the planting dates. These planting dates could be scheduled such that these phases are within "traditionally" wet months so as to fully benefit from the rainfall. This, however, could be restricted by the mill crushing season [AprilDecember] and/or incontinent weather. Interestingly, all the months with RIS values within the acceptable thresholds were found to be within the grand growth phase. This may well mean that the farmer considered the wet months at planning. 


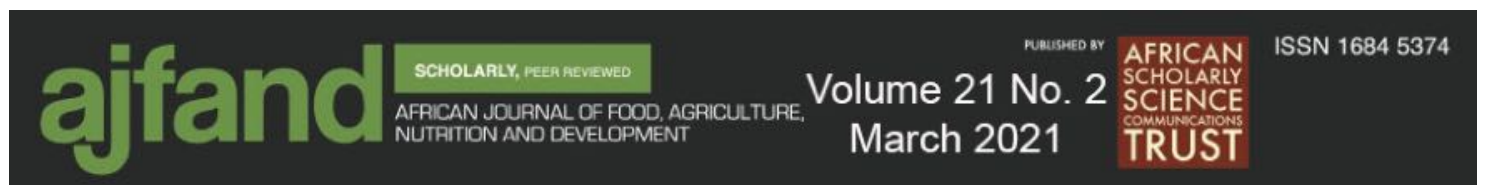

\section{CONCLUSION}

Irrigation scheduling is essential for the sugarcane crop given the yield implications of water and the ever increasing competition for water from other sectors. This study investigated irrigation adequacy in a sugarcane growing area that used a subjective irrigation scheduling approach. Annual RIS values showed that irrigation was adequate for the crop under sprinkler irrigation, whilst the area under the centre pivot was overirrigated. The monthly RIS values conversely indicated that the crop was over-irrigated most of the time ( 6 and 5 months for the area under centre pivot and sprinkler, respectively). In both irrigation systems, over-irrigation was experienced at the germination and establishment phases. In contrast, all of the months with acceptable RIS values were within the grand growth phase (with the exception of August in the area under the centre pivot system). It can, therefore, be concluded that the scheduling approach used in the area was largely based on grand growth phase of sugarcane development. It is recommended that the irrigation schedule be modified to accommodate each phase of crop development. 


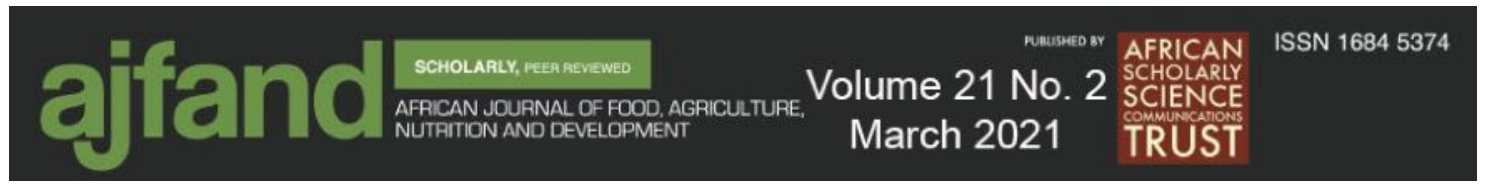

\section{REFERENCES}

1. Global Agriculture. Water 2019; https://www.globalagriculture.org/reporttopics/water.html [Accessed October 2019].

2. Mahmood R, Jia S and W Zhu Analysis of climate variability, trends, and prediction in the most active parts of the Lake Chad basin, Africa. Sci. Rep. 2019; 9(1): $1-8$.

3. Serdeczny O, Adams S, Baarsch F, Coumou D, Robinson A, Hare W, Schaeffer M, Perrette $\mathbf{M}$ and $\mathbf{J}$ Reinhardt Climate change impacts in SubSaharan Africa: From physical changes to their social repercussions. Reg. Environ. Chang. 2017; 17(6): 1585-1600.

4. Abd El-Wahed MH, Medici M and G Lorenzini Sprinkler irrigation uniformity: Impact on the crop yield and water use efficiency. J. Eng. Thermophys. 2016; 25: 117-125.

5. Annandale JG, Stirzaker RJ, Singels A, van der Laan M and MC Laker Irrigation scheduling research: South African experiences and future prospects. Water SA 2011; 37: 751-764.

6. Shongwe MI Water management practices in small-scale irrigation schemes: A case of Tugela Ferry Irrigation Scheme. UNISWA Res. J. Agric. Sci. Technol. 2008; 11: 90-100.

7. Barnard JH, van Rensburg LD, Bennie ATP and CC du Preez Water and salt balances of two shallow groundwater cropping systems using subjective and objective irrigation scheduling. Water SA 2017; 43(4): 518-594.

8. Stevens JB, Duvel GH, Steyn GJ and W Marobane The range, distribution and implementation of irrigation scheduling models and methods in South Africa. Water Research Commission, Pretoria, 2005.

9. Montagu KD and RJ Stirzaker Why do two-thirds of Australian irrigators use no objective irrigation scheduling methods. WIT Trans. Ecol. Environ. 2008; 112: $95-103$.

10. Swaziland Sugar Association. Cane testing 2017; http://www.ssa.co.sz/canetesting $/$ ?hilite= $\% 22$ pol $\% 22 \% 2 \mathrm{C} \% 22 \% 25 \% 22$ [Accessed August 2017].

11. Singels A and MT Smith Provision of irrigation scheduling advice to smallscale sugarcane farmers using a web-based crop model and cellular technology: A South African case study. Irrig. Drain. 2006; 55: 363-372.

12. Olivier FC and A Singels Survey of irrigation scheduling practices in the South African sugar industry. Proceedings of the South African Sugarcane Technologists Association; Durban, 2004; pp. 239-244. 


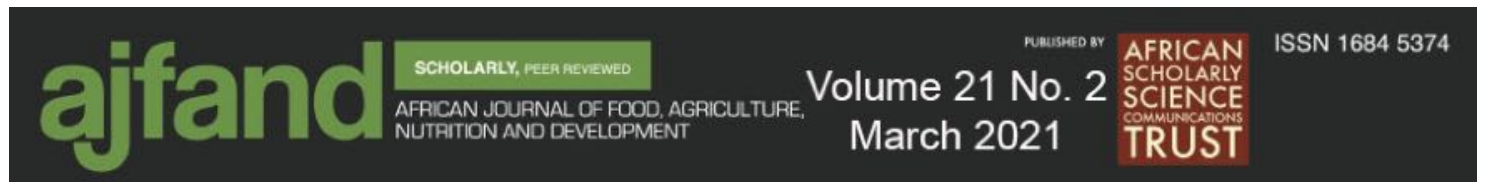

13. Gorantiwar SD and IK Smout Performance assessment of irrigation water management of heterogeneous irrigation schemes: 1. A framework for evaluation. Irrig. Drain. Syst. 2005; 19(1): 1-36.

14. Weatherbase. Nsoko, Eswatini; https://www.weatherbase.com/weather/weathersummary.php3?s $=605146 \&$ cityname $=$ Nsoko,+ Swaziland\#: $\sim:$ text $=$ Climate Summary\&text $=$ The average amount of precipitation, $0.3 \% 22(7.6 \mathrm{~mm})$ [Accessed August 2020].

15. Nixon DJ Soils of the Swaziland Sugarcane Industry. Swaziland Sugar Association and South African Sugarcane Research Institute, Mbabane, 2006.

16. Smith M CROPWAT: A computer program for irrigation planning and management. FAO Irrig. Drain. Pap. 46, 1992.

17. Zotarelli L and M Dukes Step by step calculation of the Penman-Monteith Evapotranspiration (FAO-56 Method). Institute of Food and Agricultural Sciences, University of Florida, 2010.

18. Terry AK The impact of the 2015-16 El Nino drought on the irrigated home gardens of the Komati downstream development project, Swaziland. South African Geogr. J. 2020; 102: 41-58.

19. Ali M and S Mubarak Effective rainfall calculation methods for field crops: An overview, analysis and new formulation. Asian Res. J. Agric. 2017; 7: 1-12.

20. Kharrou MH, Le Page M, Chehbouni A, Simonneaux V, Er-Raki S, Jarlan L, Ouzine L, Khabba $S$ and $G$ Chehbouni Assessment of equity and adequacy of water delivery in irrigation systems using remote sensing-based indicators in semi-arid region, Morocco. Water Resour. Manag. 2013; 27(3): 4697-4714.

21. Ascough GW and GA Kiker The effect of irrigation uniformity on irrigation water requirements. Water $S A$ 2002; 28(12): 235-242.

22. Dinka MO Evaluating the adequacy performance of sprinkler irrigation systems at Finchaa sugarcane plantation, Eastern Wollega Zone (Ethiopia). Irrig. Drain. 2016; 65(4): 537-548.

23. Remmelzwaal A and BS Masuku Characterization and correlation of the soils of Swaziland. Mbabane, 1994.

24. Smith DM, Inman-Bamber NG and PJ Thorburn Growth and function of the sugarcane root system. F. Crop. Res. 2005; 92(2-3): 169-183. 


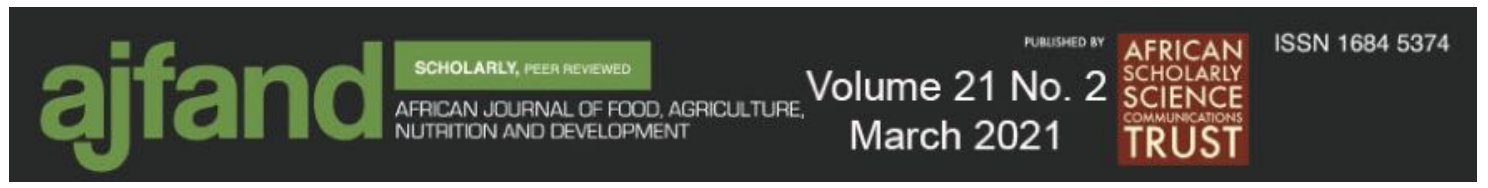

25. Allen RG, Pereira LS, Raes D and M Smith Crop evapotranspiration: Guidelines for computing crop requirements. Food and Agriculture Organization, Rome, 1998.

26. Mall RK, Sonkar G, Bhatt D, Sharma NK, Baxla AK and KK Singh Managing impact of extreme weather events in sugarcane in different agroclimatic zones of Uttar Pradesh. Mausam 2016; 67: 233-250.

27. Singh P, Singh SN, Tiwari AK, Pathak SK, Singh AK, Srivastava S and N

Mohan Integration of sugarcane production technologies for enhanced cane and sugar productivity targeting to increase farmers' income: strategies and prospects. 3 Biotech 2019; 9: 48.

28. Wang $\mathbf{X}$ and $\mathbf{Y}$ Xing Effects of irrigation and nitrogen fertilizer input levels on soil NO3-N content and vertical distribution in greenhouse tomato (Lycopersicum esculentum Mill.). Scientifica. 2016; https://doi.org/10.1155/2016/5710915

29. Wiedenfeld RP Water stress during different sugarcane growth periods on yield and response to N fertilization. Agric. Water Manag. 2000; 42: 173-182.

30. Degefa A, Bosie M, Mequanint Y, Yesuf $\mathbf{E}$ and $\mathbf{Z}$ Teshome Determination of crop water requirement of sugarcane and soybean intercropping at Metahara sugar estate. Adv. Crop Sci. Technol. 2016; 4: 215-223.

31. Robertson MJ, Inman-Bamber NG, Muchow RC and AW Wood Physiology and productivity of sugarcane with early and mid-season water deficit. F. Crop. Res. 1999; 64: 211-227.

32. Molden DJ, Sakthivadivel R, Perry CJ and C De Fraiture Indicators for comparing performance of irrigated agricultural systems. Colombo, 1998.

33. Verma IJ, Das HP and MG Ghanekar A study of water requirement of sugarcane (Saccharum officinarum L.) in gangetic plains. Mausam 2004; 55 : $339-344$. 